Nat. Hazards Earth Syst. Sci., 17, 1253-1265, 2017

https://doi.org/10.5194/nhess-17-1253-2017

(C) Author(s) 2017. This work is distributed under

the Creative Commons Attribution 3.0 License.

\title{
Synthetic tsunami waveform catalogs with kinematic constraints
}

\author{
Maria Ana Baptista ${ }^{1,2}$, Jorge Miguel Miranda ${ }^{2,3}$, Luis Matias ${ }^{2}$, and Rachid Omira ${ }^{2,3}$ \\ ${ }^{1}$ Instituto Superior de Engenharia de Lisboa, Instituto Politécnico de Lisboa, Lisbon, Portugal \\ ${ }^{2}$ Instituto Dom Luiz, Faculdade de Ciências da Universidade de Lisboa, Universidade de Lisboa, Lisbon, Portugal \\ ${ }^{3}$ Instituto Português do Mar e da Atmosfera, Lisbon, Portugal
}

Correspondence to: Maria Ana Baptista (mavbaptista@gmail.com)

Received: 31 January 2017 - Discussion started: 6 March 2017

Accepted: 30 May 2017 - Published: 21 July 2017

\begin{abstract}
In this study we present a comprehensive methodology to produce a synthetic tsunami waveform catalogue in the northeast Atlantic, east of the Azores islands. The method uses a synthetic earthquake catalogue compatible with plate kinematic constraints of the area. We use it to assess the tsunami hazard from the transcurrent boundary located between Iberia and the Azores, whose western part is known as the Gloria Fault. This study focuses only on earthquakegenerated tsunamis. Moreover, we assume that the time and space distribution of the seismic events is known. To do this, we compute a synthetic earthquake catalogue including all fault parameters needed to characterize the seafloor deformation covering the time span of 20000 years, which we consider long enough to ensure the representability of earthquake generation on this segment of the plate boundary. The computed time and space rupture distributions are made compatible with global kinematic plate models. We use the tsunami empirical Green's functions to efficiently compute the synthetic tsunami waveforms for the dataset of coastal locations, thus providing the basis for tsunami impact characterization. We present the results in the form of offshore wave heights for all coastal points in the dataset.

Our results focus on the northeast Atlantic basin, showing that earthquake-induced tsunamis in the transcurrent segment of the Azores-Gibraltar plate boundary pose a minor threat to coastal areas north of Portugal and beyond the Strait of Gibraltar. However, in Morocco, the Azores, and the Madeira islands, we can expect wave heights between 0.6 and $0.8 \mathrm{~m}$, leading to precautionary evacuation of coastal areas. The advantages of the method are its easy application to other regions and the low computation effort needed.
\end{abstract}

\section{Introduction}

Deterministic and probabilistic tsunami hazard assessment methods have been developed and applied to many geodynamic contexts and coastal areas. Deterministic assessments are scenario-based approaches, usually considering a maximum credible geological scenario for local and distant sources. They correspond to a "precautionary" approach and are a standard procedure to hazard mapping, warning procedures, and evacuation routes for highly sensitive areas, particularly critical infrastructures (González et al., 2009). Probabilistic tsunami hazard assessments providing the evaluation of the annual probability exceedance wave heights and flooding depths (Geist and Lynett, 2014) are considered more informative than a single "worst considered case" inundation scenario (LeVeque et al., 2016). In situations where the effects of smaller tsunami events are also important (e.g. interaction with harbours or other coastal structures), probabilistic hazard assessments can give a better insight into expected amplitudes and recurrence times (Geist and Parsons, 2006; Power et al., 2007; González et al., 2009; Sørensen et al., 2012; Omira et al., 2015).

Tsunami waves have several characteristics that differentiate them from other natural hazards. They can inflict significant damage away from the source area, and because of their paucity there is a limited amount of high-quality observations for the same site (Geist and Parsons, 2006). Moreover, it is not possible to describe tsunami propagation using a law-like "attenuation" and integrating it into a formal probabilistic calculation.

Probabilistic seismic hazard analysis was established by Cornell (1968) to complete the information that can be retrieved from catalogues using geological and geophysical 
information on the potential earthquake sources. Seismic events are supposed to be described by a Poisson process, and magnitudes are supposed to follow a Gutenberg and Richter (GR) doubly truncated distribution (Kijko and Graham, 1998). This approach is widely used to assess seismic hazard, particularly in areas where historical earthquake catalogues are rather incomplete. However, when the seismogenic area corresponds to a distinct plate boundary, it is possible to use the parameters given by global kinematic plate models to infer the long-term average slip on the fault and constrain the earthquake catalogue. Once the synthetic earthquake catalogue is computed, it is possible to use numerical tsunami modelling to infer the resultant tsunami waveform catalogue in an area of interest.

In this study, we define the earthquakes of the catalogue with a magnitude greater than 6 as significant seismic events, which are treated as a potential tsunami sources. We consider the simplest case of a rectangular fault with constant slip because of the location of the Gloria Fault in relation to the points of interest (POIs), and we use scaling laws to infer the fault parameters. These parameters are then used to compute the seafloor deformation using the half space elastic approach (Okada, 1985). Assuming the incompressibility of the seawater, we can directly transfer the sea bottom deformation to the water surface and use it as the initial condition for the tsunami propagation and use standard shallow water numerical modelling to provide an accurate assessment of the potential impacts close to the coasts.

The method presented here comprises three steps. The first is the computation of an earthquake synthetic catalogue compatible with long-term plate velocities covering a long time span - $20 \mathrm{kyr}$ - to ensure realistic evaluations of seismic and tsunami hazard. The second is the calculation of tsunami waveforms in selected coastal points for all events in the catalogue. The third is the post-processing of the use of synthetic tsunami waveforms to infer the impact along the coast. The computation of tsunami waveforms along the coast is a time-consuming process that requires substantial computational resources. To overcome this difficulty, we use the empirical Green's functions to compute the tsunami waveforms (see Molinari et al., 2016 and references therein) with rectangular prisms as described in Miranda et al. (2014). The use of a representative earthquake catalogue together with the fast computation of tsunami waveforms constitutes an efficient method to evaluate tsunami impact at discrete locations along the coast.

\section{Plate kinematic context}

The western segment of the Eurasian-Nubian plate boundary extends from the Mid-Atlantic Ridge in the Azores towards the Strait of Gibraltar. This plate boundary has been active since $\sim 27 \mathrm{Ma}$, when Iberia became attached to Eurasia, triggering the development of the Azores triple junction.
Spreading velocities at the Mid-Atlantic Ridge are larger for Eurasia-North America than for Nubia-North America. The tectonics of this segment of the plate boundary changes from extensional close to the Azores to transpressive close to the southwest of Iberia, where mega tsunamigenic earthquakes have been generated in the past, namely on 1 November 1755 (Baptista et al., 1998). Between Azores and Iberia it corresponds broadly to a dextral transcurrent relative motion, where there is an age difference between a younger "Eurasian" lithosphere, to the north, and an older "Nubian" lithosphere to the south (Luis and Miranda, 2008).

The geometry of this plate boundary was studied since the early years of plate tectonics (e.g. McKenzie, 1972). Between -24 and $-20^{\circ} \mathrm{E}$, the plate boundary is supposed to follow a prominent morphological feature, the Gloria Fault (see Fig. 1). This fault, first mapped by Laughton et al. (1972), is a $400 \mathrm{~km}$ long fracture, with a vertical offset of several hundreds of metres (this is the Gloria Fault s.s.). Between -20 and $-18^{\circ} \mathrm{E}$ it changes strike, from N84E to N71E (Baptista et al., 2016). East of $-18^{\circ} \mathrm{E}$ the strike of the main structure changes to N98E, joining the Tore-Madeira Rise close to $-15.5^{\circ} \mathrm{E}$. Here, there is not a unique fracture zone that could be interpreted as the plate boundary. East of the Tore-Madeira Rise the geometry of the Eurasia-Nubia plate boundary is still a matter of debate.

Current plate kinematic models show that both the first and the third segments of the plate boundary follow an inner circle of the Nubia-Eurasia relative plate velocity very closely, with an estimated value of $4 \mathrm{~mm} \mathrm{yr}^{-1}$ (e.g. Fernandes et al., 2003, and references therein). Tectonically, both segments can be interpreted as dextral transcurrent faults with minor compressive or normal components. Nevertheless, during the 20th century three earthquakes of magnitude greater than 7 occurred in this plate boundary, all of them tsunamigenic: on 8 May 1939, $M_{\mathrm{S}} 7.1$ (Reis et al., 2016); on 25 November 1941, $M 8.3$ (Baptista et al., 2016); and on 26 May 1975, M 7.9 (Buforn et al., 1988; Kaabouben et al., 2008). The 1939 earthquake and tsunami had its source close to the Azores, at $-24.34^{\circ} \mathrm{E}, 37.17^{\circ} \mathrm{N}$, on the western tip of the Gloria Fault (Buforn et al., 1988; Reis et al., 2016). The 1941 earthquake and tsunami, one of the largest submarine strike-slip events ever recorded, had its source at $-19.04^{\circ} \mathrm{E}$, $37.41^{\circ} \mathrm{N}$, close to the middle of the plate boundary (Udias et al., 1976; Lynnes and Ruff, 1985; Baptista et al., 2016). The 1975 earthquake had its epicentre close to $-17.50^{\circ} \mathrm{E}$, $35.90^{\circ} \mathrm{N}$, on the eastern part of the plate boundary, $200 \mathrm{~km}$ to the south of Gloria Fault. The spatial distribution of these three events shows that there is not a single discrete structure running from the Azores to Gibraltar (see Fig. 1), which can be considered as the locus of seismic slip.

To compute the synthetic earthquake catalogue, we assume a simplified interpretation model with three homogeneous sections. The first one, between -24 and $-18.5^{\circ} \mathrm{E}$, is to the west of the 1941 earthquake epicentre named segment GF1. To the east of GF1 we consider a split into two 


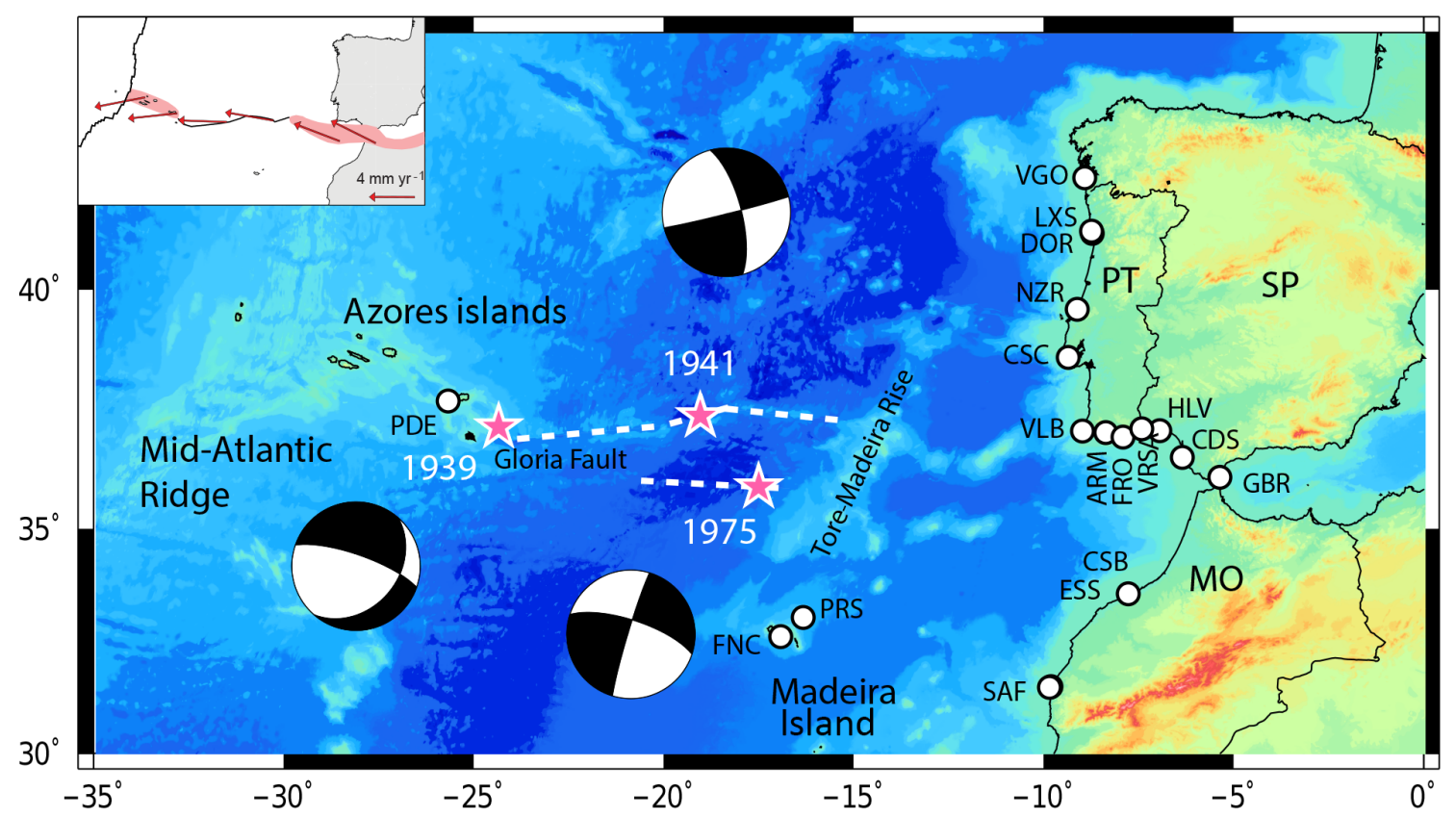

Figure 1. Shaded bathymetry map of Iberia, northwest Africa, and the central Atlantic. The three pink stars correspond to the epicentres of the large strike-slip events in the study area (see text for details). The points of interest used in this study are: VGO (Vigo), LXS (Leixões), DOR (Douro), NZR (Nazaré), CSC (Cascais), VLB (Vila do Bispo), ARM (Armação), FRO (Faro), VRSA (Vila Real de Santo António), HLV (Huelva), CDS (Cádis), GBR (Gibraltar), CSB (Casablanca), ESS (Essaouira), SAF (Safi), PRS (Porto Santo), FNC (Funchal), and PDE (Ponta Delgada). PT (Portugal); SP (Spain); MO (Morocco). Inset shows the relative velocities between Nubian and Eurasia plates. Focal mechanisms for the three largest instrumental earthquakes are also shown according to Table 1.

subparallel segments, GF2 and GF3 (see Fig. 2). These two subsegments might correspond to the reactivation of previous transform faults associated with the Mid-Atlantic Ridge; the northern segment follows the shape of the Gloria Fault, and the southern segment corresponds to the most probable location of the 26 May 1975 event (Lynnes and Ruff, 1985, and Kaabouben et al., 2008). Figure 2 depicts this model.

\section{Computation of the synthetic earthquake catalogue}

\subsection{Scaling laws for tsunamigenic sources in the Gloria Fault}

In this study, we assume that the coseismic displacement can be described by the half space elastic approach following Okada (1985). We use nine independent parameters: fault width $W$, fault length $L$, fault azimuth (strike) $\varphi$, dip angle $\delta$, average slip along the fault $u$, slip angle (rake) $\lambda$, and depth below seafloor $h$ to describe each seismic event of the synthetic catalogue. Here, "epicentre" is the geometrical centre of the rectangular fault, which adds two parameters to the list above, $f_{\text {lat }}$ and $f_{\text {lon }}$. The seismic moment $M_{0}$ is related with the fault area $A=W L$, and the average slip $u$, by

$M_{0}=\mu A u$.
The relation between the moment magnitude $M_{\mathrm{w}}$ and the seismic moment $M_{0}$ is given by Eq. (2) (Hanks and Kanamori, 1979):

$M_{\mathrm{w}}=\frac{2}{3}\left(\log M_{0}-9.05\right)$.

In Eqs. (1) and (2), $\mu$ is the modulus of rigidity. Given the moment release and the rupture area, the stress drop $\Delta \sigma$ can be inferred by

$\Lambda \Delta \sigma=\frac{C M_{0}}{W L}$.

In Eq. (3), $C$ and $\Lambda$ are constants that depend on the fault mechanism and geometry. For rectangular strike-slip faults, the most appropriate constants for $C$ and $\Lambda$ are given by $C=$ $2 / \pi$ and $\Lambda=W$ (Kanamori and Anderson, 1975).

Assuming that all events of the catalogue occur inside the same tectonic area, the dip, strike, and rake angles, and the modulus of rigidity can be considered as independent of the magnitude. We describe these parameters by random variables characterized by their mean and standard deviation, with a normal or log-normal distribution: $\left(\overline{\delta,} \sigma_{\delta}\right),\left(\bar{\phi}, \sigma_{\phi}\right)$, $\left(\overline{\lambda,} \sigma_{\lambda}\right)$, and $\left(\overline{\mu,} \sigma_{\mu}\right)$. The length, width, and slip of the fault constrain the magnitude and can be considered as random variables: $\left[\bar{W}\left(M_{\mathrm{w}}\right) \sigma_{w}\right],\left[\bar{L}\left(M_{\mathrm{w}}\right) \sigma_{L}\right]$, and $\left[\bar{u}\left(M_{\mathrm{w}}\right) \sigma_{u}\right]$. The relations between these three parameters are given by 


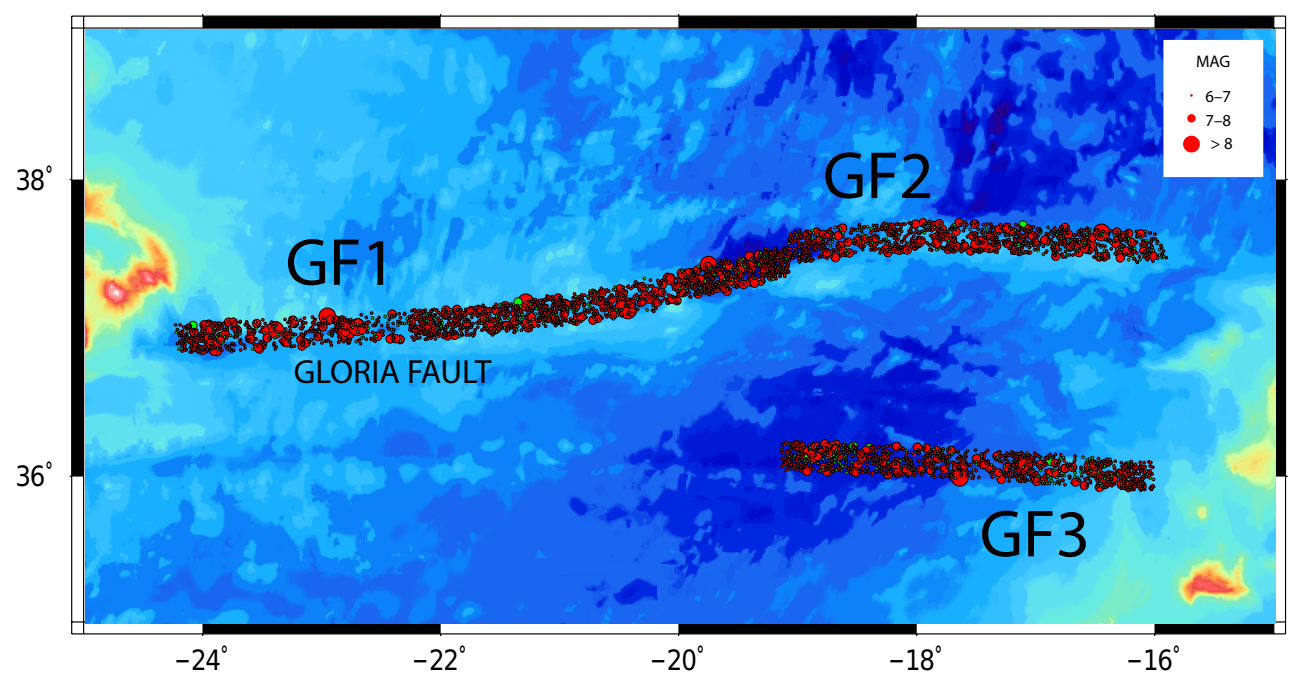

Figure 2. Decomposition of Gloria Fault into three main segments: GF1, GF2, and GF3. The red dots correspond to the epicentre distribution as given by the seismic catalogue. Green circles correspond to deep earthquakes (depth greater than $30 \mathrm{~km}$ ).

Table 1. Summary of the main seismotectonic parameters related to the two largest events occurred during instrumental times in the Gloria Fault area.

\begin{tabular}{lrrrrrrrrr}
\hline Event & $\begin{array}{r}\mu \\
10^{10} \mathrm{~Pa}\end{array}$ & $M_{\mathrm{W}}$ & $\begin{array}{r}L \\
\mathrm{~km}\end{array}$ & $\begin{array}{r}W \\
\mathrm{~km}\end{array}$ & $\begin{array}{r}u \\
\mathrm{~m}\end{array}$ & $\begin{array}{r}\Delta \sigma \\
\mathrm{MPa}\end{array}$ & Strike & Dip & Rake \\
\hline $1941^{\mathrm{a}}$ & 3.0 & 8.3 & 200 & 45 & 12 & 5.6 & 76 & 88 & -161 \\
$1941^{\mathrm{b}}$ & 5.0 & 8.4 & 200 & 45 & 12 & 9.6 & 76 & 88 & -161 \\
$1975^{\mathrm{c}}$ & 4.0 & 7.9 & 80 & 20 & 11 & 14 & 288 & 72 & -176 \\
$1975^{\mathrm{d}}$ & 4.0 & 7.9 & 200 & 45 & 2.5 & 1.1 & 288 & 72 & -176 \\
\hline
\end{tabular}

${ }^{a}$ Lynnes and Ruff (1985), Baptista et al. (2016). ${ }^{\text {b }}$ Modified from Lynnes and Ruff (1985) according to the proposed higher rigidity modulus. ${ }^{c}$ Lynnes and Ruff (1985). ${ }^{d}$ Length from Buforn et al. (1988).

Eqs. (1) and (2), and we assume that slip on the fault is the parameter to be adjusted. In addition, we assume a dominant strike slip regime with a maximum magnitude estimated at 8.5 (the 25 November 1941 event has an estimated magnitude $M_{\mathrm{s}}=8.2$ to 8.4; Gutenberg and Richter, 1949; Udias et al., 1976). Considering that we have oceanic lithosphere with a typical oceanic crust ( $7 \mathrm{~km}$ thick) and very few or no sediments, we will use $5.0 \times 10^{10} \mathrm{~Pa}$ for the rigidity modulus $(\mu)$. Table 1 presents a summary of the main seismotectonic parameters related to the two largest instrumental events in this plate boundary.

We include in Table 1 the source length proposed by $\mathrm{Bu}-$ forn et al. (1988) for the 1975 earthquake. The width was considered to be $45 \mathrm{~km}$, meaning a complete rupture of the brittle oceanic lithosphere, as estimated from its age. The aspect ratio is then 4, which is identical to the ones considered for the other three entries. With these constraints, the estimated average slip and stress drop are computed. We note that the estimated stress drop reduces considerably to $1.1 \times 10^{10} \mathrm{~Pa}$ and the average slip is only $2.5 \mathrm{~m}$. This last result is in contradiction with the tsunami modelling results by
Kaabouben et al. (2008), which considered an average slip on the fault of $11 \mathrm{~m}$ adequate to reconcile tsunami observations with the source. The low value of stress drop that results from the Buforn et al. (1988) source length is also in contradiction with the intra-plate setting of this earthquake and at odds with the stress drop inferred for the 1941 event. The knowledge of the stress drop is also important for the stochastic simulation of strong motion recordings, and Carvalho et al. (2016) obtained a mean value of stress drop in the Azores area between 9 and $13 \mathrm{MPa}$. These will be our reference values in establishing a scaling law for the Gloria Fault earthquakes.

To obtain the scaling relationship between the magnitude, the fault dimensions, and the average slip, we analysed three compilations: (i) Wells and Coppersmith (1994) (WC94), (ii) Stirling et al. (2002) (S2002), and (iii) Blaser et al. (2010) (B2010). Considering the characteristics of the Azores-Gibraltar plate boundary, we selected only the faults and laws with pure strike-slip mechanisms. As the first compilation includes incomplete information on subsurface rupture length, we computed an average relationship between 
Table 2. Scaling laws for the width, length, and average slip derived from the compilations by Stirling et al. (2002), Wells and Coppersmith (1994), and Blaser et al. (2010).

\begin{tabular}{|c|c|c|c|c|c|c|c|c|c|c|c|c|c|c|c|c|c|c|c|}
\hline \multirow[t]{2}{*}{$M_{\mathrm{W}}$} & \multirow[t]{2}{*}{$\begin{array}{l}M_{0} \\
\mathrm{Nm}\end{array}$} & \multicolumn{6}{|c|}{$\begin{array}{l}\text { Stirling et al. (2002) } \\
\qquad \mu=5 \times 10^{10} \mathrm{~Pa}\end{array}$} & \multicolumn{6}{|c|}{$\begin{array}{l}\text { Wellsand Coppersmith (1994) } \\
\qquad \mu \sim 4.4 \times 10^{10} \mathrm{~Pa}\end{array}$} & \multicolumn{6}{|c|}{$\begin{array}{l}\text { Blaser et al. (2010) } \\
\mu=5 \times 10^{10} \mathrm{~Pa}\end{array}$} \\
\hline & & $\begin{array}{r}L \\
\mathrm{~km}\end{array}$ & $\begin{array}{r}W \\
\mathrm{~km}\end{array}$ & $\begin{array}{l}u \\
\mathrm{~m}\end{array}$ & $\begin{array}{r}A \\
\mathrm{~km}^{2}\end{array}$ & $L / W$ & $\begin{array}{r}\Delta \sigma \\
\mathrm{MPa}\end{array}$ & $\begin{array}{r}L \\
\mathrm{~km}\end{array}$ & $\begin{array}{r}W \\
\mathrm{~km}\end{array}$ & $\begin{array}{l}u \\
\mathrm{~m}\end{array}$ & $\begin{array}{r}A \\
\mathrm{~km}^{2}\end{array}$ & $L / W$ & $\begin{array}{c}\Delta \sigma \\
\mathrm{MPa}\end{array}$ & $\begin{array}{r}L \\
\mathrm{~km}\end{array}$ & $\begin{array}{r}W \\
\mathrm{~km}\end{array}$ & $\begin{array}{l}u \\
\mathrm{~m}\end{array}$ & $\begin{array}{r}A \\
\mathrm{~km}^{2}\end{array}$ & $L / W$ & $\begin{array}{r}\Delta \sigma \\
\mathrm{MPa}\end{array}$ \\
\hline 6.50 & $6.31 \times 10^{18}$ & 32.7 & 10.4 & 0.37 & 339 & 3.16 & 0.90 & 32.8 & 11.9 & 0.29 & 391 & 2.76 & 0.86 & 29.5 & 10.6 & 0.40 & 313 & 2.79 & 1.21 \\
\hline 6.75 & $1.50 \times 10^{19}$ & 48.8 & 11.6 & 0.53 & 567 & 4.20 & 1.14 & 45.7 & 12.8 & 0.51 & 583 & 3.59 & 1.28 & 42.7 & 12.8 & 0.55 & 546 & 3.33 & 1.36 \\
\hline 7.00 & $3.55 \times 10^{19}$ & 72.8 & 13.0 & 0.75 & 947 & 5.59 & 1.44 & 63.7 & 13.7 & 0.88 & 869 & 4.66 & 1.90 & 61.7 & 15.5 & 0.74 & 955 & 3.98 & 1.53 \\
\hline 7.25 & $8.41 \times 10^{19}$ & 109 & 14.6 & 1.06 & 1582 & 7.44 & 1.82 & 88.6 & 14.6 & 1.53 & 1296 & 6.06 & 2.82 & 89.1 & 18.7 & 1.01 & 1669 & 4.76 & 1.71 \\
\hline 7.50 & $2.00 \times 10^{20}$ & 162 & 16.3 & 1.51 & 2644 & 9.89 & 2.31 & 123 & 15.7 & 2.66 & 1933 & 7.88 & 4.19 & 129 & 22.6 & 1.37 & 2917 & 5.69 & 1.92 \\
\hline 7.75 & $4.73 \times 10^{20}$ & 241 & 18.3 & 2.14 & 4417 & 13.2 & 2.92 & 172 & 16.8 & 4.63 & 2883 & 10.2 & 6.23 & 186 & 27.4 & 1.86 & 5099 & 6.80 & 2.16 \\
\hline 8.00 & $1.12 \times 10^{21}$ & 359 & 20.5 & 3.04 & 7381 & 17.5 & 3.70 & 239 & 18.0 & 8.03 & 4298 & 13.3 & 9.25 & 269 & 33.1 & 2.52 & 8913 & 8.13 & 2.42 \\
\hline 8.25 & $2.66 \times 10^{21}$ & 536 & 23.0 & 4.31 & 12332 & 23.3 & 4.69 & 333 & 19.2 & 14.0 & 6410 & 17.3 & 13.73 & 389 & 40.0 & 3.42 & 15578 & 9.72 & 2.72 \\
\hline 8.50 & $6.31 \times 10^{21}$ & 799 & 25.8 & 6.12 & 20606 & 31.0 & 5.93 & 464 & 20.6 & 24.2 & 9558 & 22.5 & 20.39 & 562 & 48.4 & 4.63 & 27227 & 11.6 & 3.05 \\
\hline
\end{tabular}

surface and subsurface lengths as $L_{\text {subsurface }}=1.65 L_{\text {superficial }}$ to estimate the length of the fault as the subsurface rupture for all the earthquakes where the width and average displacement on the fault are also known. The B2010 model improves on the WC94 database by adding 163 new earthquakes from other sources. Blaser et al. (2010) recognize that WC94 scaling laws were dominated by earthquakes in the continents, while the new relationships added a significant number of new events along oceanic subduction zones. This is the reason why the two sets of relationships are different from each other (ibid.). However, the oceanic strike-slip faults continue to be very poorly represented in this new dataset. None of the events presented in Blaser et al. (2010) can be considered as a proxy for the Gloria Fault seismotectonic environment. Table 2 presents a summary of these results.

There are several undesirable features in the case of the use of the Stirling et al. (2002) database. These features are the large variations of the stress drop with magnitude, the large changes of the fault aspect ratio with moment magnitude, and the lack of agreement with the largest events recorded in the area (see Table 1). The scaling laws derived from Wells and Coppersmith (1994), also presented in Table 2 , are more satisfactory regarding the comparison with those largest events, but, still, they show large changes in the stress drop with magnitude. These effects may be a consequence of the prevalence of continental strike-slip faults and ridge offset transforms in both compilations, as they are rheologically different from intra-oceanic events. The Blaser et al. (2010) compilation shows the same problems as S2002 large variability in the fault aspect ratio and low stress drop.

To circumvent these limitations, we adopted a semiempirical approach aimed at keeping a nearly constant fault aspect ratio and a high stress drop compatible with the few observations available. We applied the methodology used by Matias et al. (2013) for the tsunamigenic sources in the Gulf of Cádiz, based on the works of Scholz (1982). We start from the scaling relationships of Manighetti et al. (2007):

$$
\begin{aligned}
& D_{\max }=\frac{\alpha L}{2} \quad \text { if } \quad L \leq 2 W_{\text {sat }}, \\
& D_{\max }=\frac{\alpha}{\frac{1}{L}+\frac{1}{2 W_{\text {sat }}}} \quad \text { if } \quad L>2 W_{\text {sat }} .
\end{aligned}
$$

Here, $D_{\max }$ is the maximum displacement on the fault, $L$ is the fault length, and $W_{\text {sat }}$ is the saturation width, which we take as the maximum rupture thickness. We consider $D_{\max }=2 D$ as in Manighetti et al. (2007), $\alpha=50 \times 10^{-5}$. Since the oceanic crust age at the Gloria Fault changes from 50 Myr to the West to 120 Myr to the east (Luis and Miranda, 2008), we assume that the $600^{\circ} \mathrm{C}$ isotherm depth ranges from 35 to $52 \mathrm{~km}$, with an average value of $40 \mathrm{~km}$ for the seismogenic thickness in the whole Gloria Fault area (e.g. McKenzie et al., 2005; Geli and Sclater, 2008), thus $W_{\text {sat }}=40 \mathrm{~km}$. We consider that the typical aspect ratio $f=L / W$ is close to 4.0 for fault rupture in the Gloria Fault area.

When $L \leq 2 W_{\text {sat }}, W$ is obtained from a simple linear relationship (Eq. 4 , case 1 in Table 3). When $L>2 W_{\text {sat }}$, the fault width $W$ must be derived by solving a third degree polynomial equation (case 2 in Table 3). In addition, we know that thermo-mechanical properties of the oceanic lithosphere restrict the seismic rupture to the seismogenic layer (or a little more for very large earthquakes). In our source model, we limit the width of the fault to the seismogenic thickness as discussed above. Therefore, when $L>2 W_{\text {sat }}$ and $W>W_{\max }$, the fault width $W$ is obtained by solving a second degree polynomial equation (case 3 in Table 3 ). Results for the study area are depicted in Fig. 3, together with the few instrumental large earthquakes, and the Robinson (2011) solution for the 2004 December $23 M_{\mathrm{w}}=8.1$ Tasman Sea oceanic intraplate strike-slip event, which can be considered a comparable event.

The magenta curve in Fig. 3 depicts the final scaling law between fault displacement and fault length. Scaling laws for width, length, and average slip are depicted in Table 3. By using this scaling law there is a high but nearly constant stress 
Table 3. Scaling laws for the width, length, and average slip derived by a semi-empirical approach.

\begin{tabular}{rrrrrrrrr}
\hline$M_{\mathrm{W}}$ & $\begin{array}{r}M_{0} \\
(\mathrm{Nm})\end{array}$ & $\begin{array}{r}L \\
(\mathrm{~km})\end{array}$ & $\begin{array}{r}W \\
(\mathrm{~km})\end{array}$ & $\begin{array}{r}u \\
(\mathrm{~m})\end{array}$ & $\begin{array}{r}A \\
\left(\mathrm{~km}^{2}\right)\end{array}$ & $\begin{array}{l}\Delta \sigma \\
(\mathrm{MPa})\end{array}$ & $\begin{array}{r}\text { Case } \\
\end{array}$ \\
\hline 6.50 & $6.31 \times 10^{18}$ & 16.6 & 4.15 & 2.08 & 69.0 & 4.0 & 15.9 & 1 \\
6.75 & $1.50 \times 10^{19}$ & 22.1 & 5.54 & 2.77 & 123 & 4.0 & 15.9 & 1 \\
7.00 & $3.55 \times 10^{19}$ & 29.5 & 7.38 & 3.69 & 218 & 4.0 & 15.9 & 1 \\
7.25 & $8.41 \times 10^{19}$ & 39.4 & 9.8 & 4.92 & 388 & 4.0 & 15.9 & 1 \\
7.50 & $2.00 \times 10^{20}$ & 52.5 & 13.1 & 6.57 & 690 & 4.0 & 15.9 & 1 \\
7.75 & $4.73 \times 10^{20}$ & 70.0 & 17.5 & 8.75 & 1226 & 4.0 & 15.9 & 1 \\
8.00 & $1.12 \times 10^{21}$ & 96.5 & 24.1 & 10.9 & 2329 & 4.0 & 14.4 & 2 \\
8.25 & $2.66 \times 10^{21}$ & 138 & 34.5 & 12.7 & 4769 & 4.0 & 11.7 & 2 \\
8.50 & $6.31 \times 10^{21}$ & 239 & 40.0 & 15.0 & 9559 & 6.0 & 11.9 & 3 \\
\hline
\end{tabular}

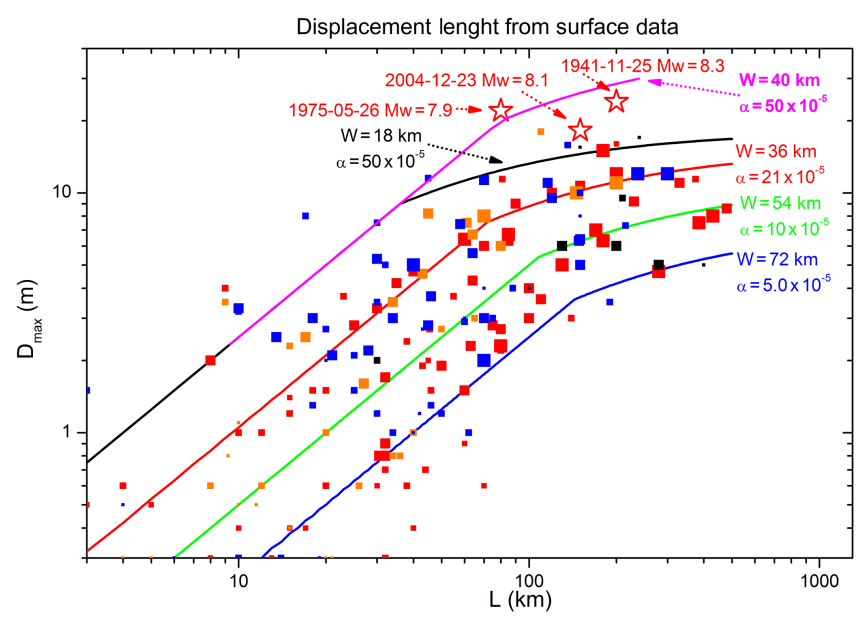

Figure 3. Maximum displacement versus fault length derived from surface measurements (adapted from Manighetti et al. 2007): red squares, strike-slip events; orange squares, dip-slip events; blue squares, composite faults. The black squares were not used in the regression analysis. The size of the symbols is proportional to the quality of the data. Also represented are the four typical laws selected by the automatic regression of Manighetti et al. (2007; coloured lines). The data points for the Gloria Fault and Tasman Sea earthquakes are plotted as red stars, and the magenta line depicts the adopted scaling law (see text for details).

drop and a constant aspect ratio until the rupture exceeds the seismogenic thickness.

\subsection{Earthquake recurrence}

Earthquake recurrence for the Azores-Gibraltar transcurrent plate boundary cannot be assessed from historical information or instrumental catalogues, due to the location of the plate boundary with respect to the neighbouring land areas and the resulting incompleteness of catalogues. Nevertheless, one may consider that the time distribution of earthquakes can be described by a truncated GR law, with the cumulative distribution function given by Kijko and Graham (1998):

$$
\begin{aligned}
& F_{M}\left(m \mid m_{\min }, m_{\max }\right)=0 \quad \text { if } \quad m<m_{\min }, \\
& \frac{1-e^{-\beta\left(m-m_{\min }\right)}}{1-e^{-\beta\left(m_{\max }-m_{\min }\right)}} \text { if } \quad m_{\min } \leq m \leq m_{\max }, \\
& 1 \quad \text { if } \quad m>m_{\max } .
\end{aligned}
$$

Here $m_{\min }$ is the minimum magnitude of interest, $m_{\max }$ is the maximum earthquake magnitude for the Gloria Fault, and $\beta=b \ln (10)$, with $b$ being the usual GR parameter. Assuming a Poisson distribution, and taking $\lambda$ as the yearly mean occurrence of earthquakes with a magnitude greater than the threshold value $m_{\min }$, the mean rate of occurrence of earthquakes with magnitude equal to or greater than $m$ ( $\left.m_{\min } \leq m \leq m_{\max }\right)$ is given by Eq. (6):

$\dot{N}(m)=\lambda\left[1-F_{M}\left(m \mid m_{\min }, m_{\max }\right)\right]$.

Considering the segmentation of Gloria Fault as described in Sect. 2, the lengths of GF1, GF2, and GF3 are 455, 271, and $278 \mathrm{~km}$ respectively (cf. Fig. 2). We consider that plate kinematic strain is fully coupled to GF1 section but split in two between sections GF2 and GF3. We deduce the maximum magnitude $m_{\max }$ of each section from the previous scaling laws. The maximum magnitudes are 8.5, 8.1, and 8.1 for segments GF1, GF2, and GF3 respectively, corresponding to the rupture of the entire segment. We assume that the faults are vertical with a maximum width of $40 \mathrm{~km}$. We consider a modulus of rigidity of $\mu=5.0 \times 10^{10} \mathrm{~Pa}$, a seismic coupling coefficient between plate kinematics and earthquake generation $\chi=1.0$ for all fault segments, and $b(\beta)=0.98$, as estimated by Bird and Kagan (2004) for slow oceanic transform faults. Considering $m_{\min }=6.0$ we can estimate earthquake activity rate $\lambda$. This is done by summing the total seismic moment generated and computing the activity rate that fits exactly the kinematic constrains. The parameters for the truncated Gutenberg-Richter law are summarized in Table 4.

We generated the seismic synthetic catalogue for a total time span of $20 \mathrm{kyr}$, using the MATLAB code provided by Andrzej Kijko (Kijko and Graham, 1998). It estimates the 

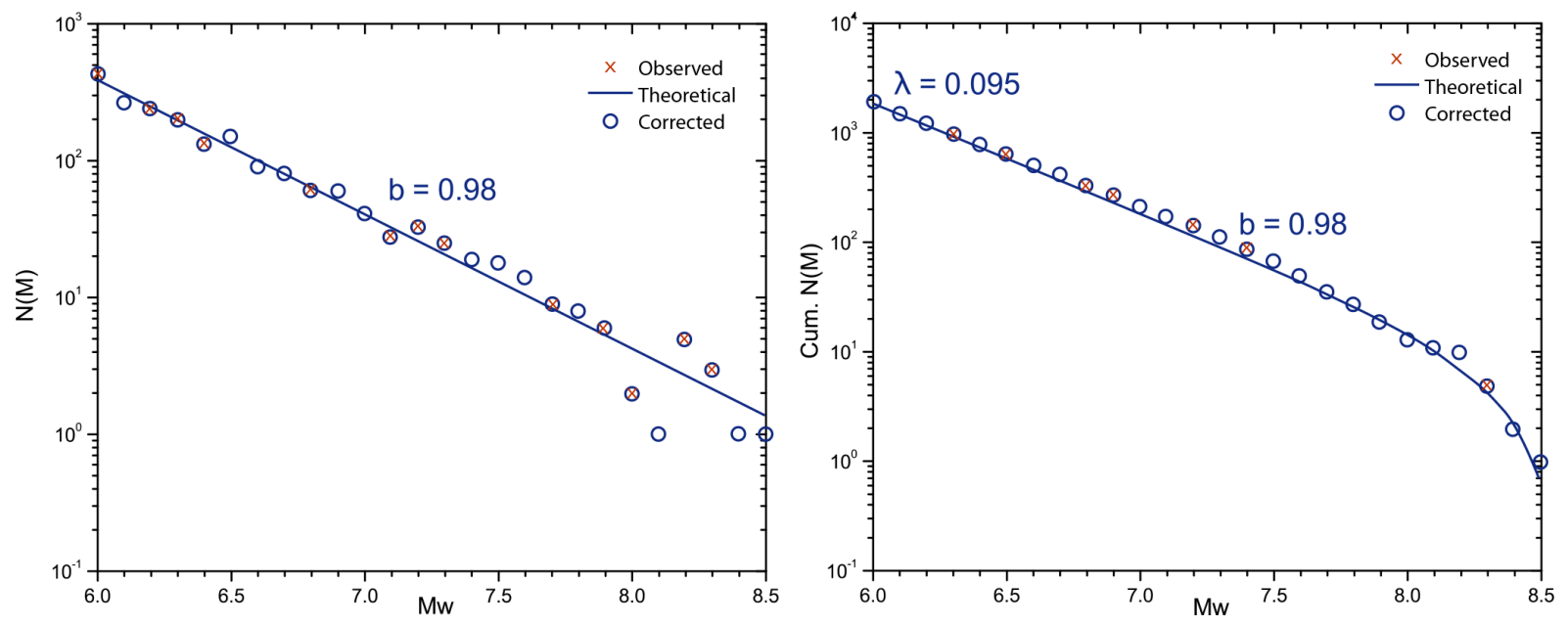

Figure 4. Comparison of the adopted synthetic catalogue generated for the GF1 section and the GR model (blue line). The catalogue values are in red. The blue circles show the corrected number of earthquakes to attain the nominal slip rate.

Table 4. Summary of truncated Gutenberg-Richter laws for the active sources in the Gloria Fault area.

\begin{tabular}{lrrrrrrr}
\hline & $M_{\min }$ & $M_{\max }$ & $\begin{array}{r}L \\
(\mathrm{~km})\end{array}$ & $\begin{array}{r}W \\
(\mathrm{~km})\end{array}$ & $b$ & $\begin{array}{r}\lambda \\
\left(\mathrm{yr}^{-1}\right)\end{array}$ & $\begin{array}{r}\dot{u} \\
\left(\mathrm{~mm} \mathrm{yr}^{-1}\right)\end{array}$ \\
\hline GF1 & 6.0 & 8.5 & 455 & 40 & 0.98 & 0.095 & 4.0 \\
GF2, GF3 & 6.0 & 8.1 & 275 & 40 & 0.98 & 0.054 & 2.0 \\
\hline
\end{tabular}

time interval between events assuming a Poisson distribution and then computes the magnitude of each earthquake by extracting a random value from the magnitude cumulative distribution function defined by a truncated Gutenberg-Richter law.

We compared the synthetic catalogue with the GutenbergRichter model that generated it, and the sum of the seismic moment generated was compared with the nominal slip rate as given by plate kinematic models $\left(\sim 4 \mathrm{~mm} \mathrm{yr}^{-1}\right.$, e.g. Fernandes et al., 2003). Different random generations of the synthetic catalogue showed significant fluctuations in the number of earthquakes generated for large magnitudes and, consequently, in the total slip rate. We compensated for these differences by extending or reducing the time span of the catalogue. For further analysis, we selected one run of the synthetic catalogue that showed less fluctuation in the generation of large earthquakes and consequently a small discrepancy with the nominal kinematic constraint. The earthquake recurrence for this catalogue is shown in Fig. 4.

Given the time sequence of earthquakes in the synthetic catalogue for the whole area, we need to attribute each event to the best location, ensuring compliance with the kinematic constraints. To do this, we use a rectangular model of the fault plane divided into small elements $1 \times 1 \mathrm{~km}^{2}$. The slip on the fault is initialized with a smoothed random function with zero average (Fig. 5). Next, for each event in the catalogue, we search all possible locations for the fault rupture and select the one with the smallest total slip. Once the location is selected, the corresponding slip on the rectangular rupture area is applied, and we proceed until the whole catalogue is exhausted. The success of the procedure can be evaluated by the final cumulated slip on the fault segments shown in Fig. 5b. The colour scheme used emphasizes the irregular slip distribution that results from the methodology. However, when compared to the nominal slip, we see that extreme values are limited in space and not systematically distributed, as would be expected from a uniform random distribution of earthquakes. Further improvements on the method could include irregular slip distributions for each earthquake. Without any changes in the methodology, the results can be also applied to an earthquake generation mechanism that explains the variability in cumulated slip by variations in seismic coupling from patch to patch. Then, we would only need to adjust the time span of the catalogue to convert the modelled high slip rates to its kinematic nominal value.

To complete the parameters needed for the computation of the tsunami source, we use the mean geometrical parameters of Gloria Fault. For each event we compute the epicentre coordinates, strike, dip, and rake, using a Gaussian random generator. The standard deviations are as follow: epicentre coordinates, $\pm 0.1^{\circ}$; fault strike, $\pm 5^{\circ}$; fault dip, $85 \pm 5^{\circ}$; and slip rake, $170 \pm 5^{\circ}$. Figure 2 shows the final epicentre distribution. 

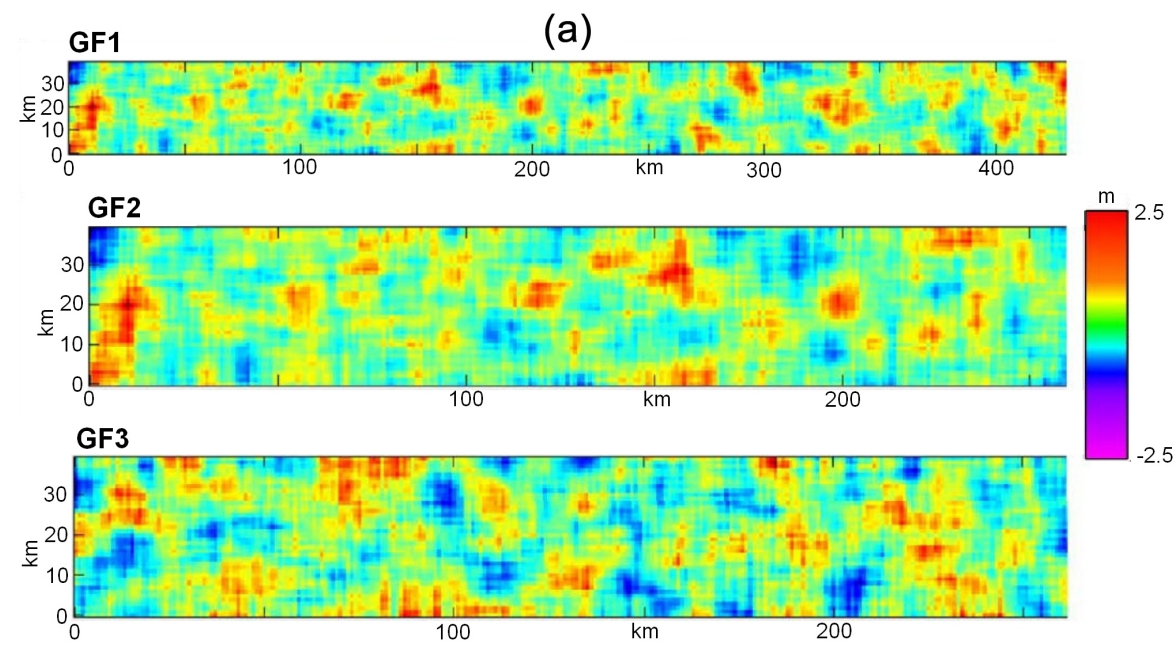

(b)
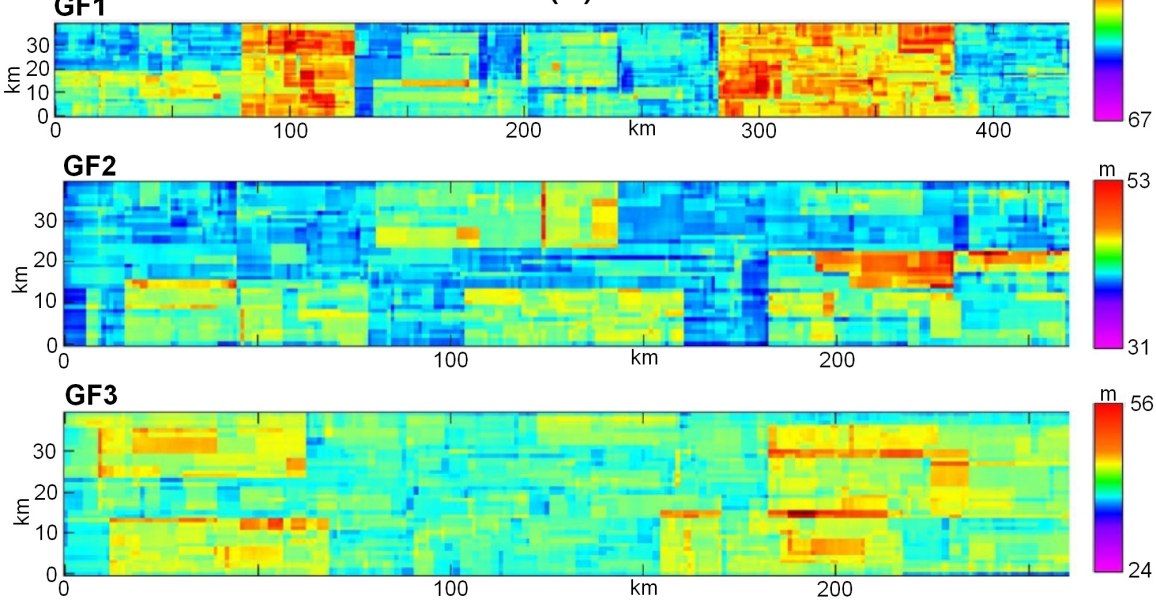

Figure 5. (a) Initial slip on the Gloria Fault active sections (GF1, GF2, and GF3) after a smoothed random slip generation, with zero mean. (b) Final slip on the Gloria Fault sections after 20000 years of a synthetic catalogue. Minimum, maximum, and nominal cumulated slips are (in m) GF1 (67 to 97, 80), GF2 (30 to 53, 40), and Gf3 (24 to 55, 40).

\section{Tsunami waveform simulation}

The use of the empirical Green's functions to compute the tsunami waveforms associated with a given earthquake source in a collection of points of interest presented by Miranda et al. (2014) includes the following four steps: (i) the definition of an area where the initial sea surface displacement is significantly different from zero for all possible sources under study; (ii) the partition of the source area into unit prisms of water $1 \mathrm{~m}$ high, where the length and width of those prisms are as small as possible to ensure a good description of the initial displaced area; (iii) the definition of a set of points of interest along the coast, which correspond to the location where hazard is to be computed; and (iv) the computation of the tsunami waveforms at all POIs due to unit prisms, using a linear shallow water model. These four com- ponents form the empirical Green's function database for the study area.

We define as relevant source area the region where the initial sea surface displacement caused by the coseismic deformation is significantly different from zero (in this case $>10 \mathrm{~cm}$ ). Considering the close clustering of seismic activity around Gloria Fault, we defined the rectangular domain $25-14^{\circ} \mathrm{W}, 35-39^{\circ} \mathrm{N}$ as the relevant source area. We divided this area into 110 (longitude) $\times 40$ (latitude) unit sources, with $0.1^{\circ} \times 0.1^{\circ}$. The empirical Green's function for each unit source was done using the code NSWING (Miranda et al., 2014).

NSWING (Nonlinear Shallow Water With Nested Grids) is an implementation based on Liu et al. (1998), like COMCOT, entirely written in $C$, with an easy-to-use interface following the Generic Mapping Tools (Wessel et. al., 2013) style and core parallelization to foster computing perfor- 


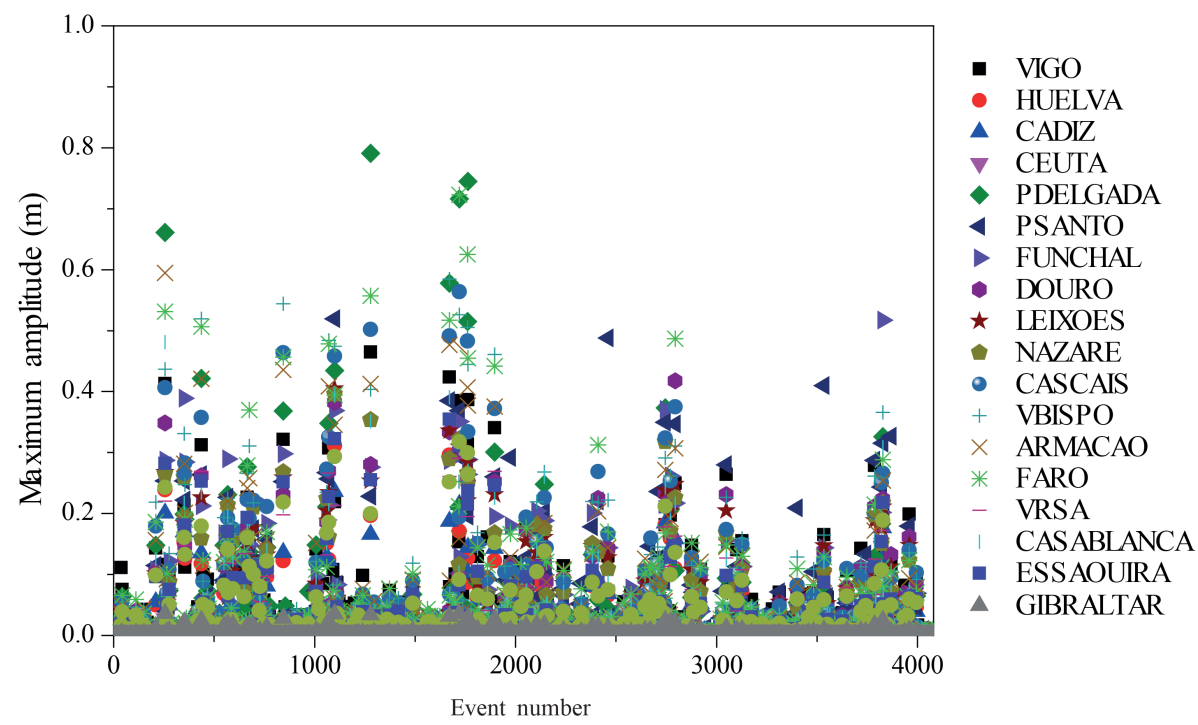

Figure 6. Time distribution of tsunami wave heights at the points of interest, for the entire catalog. The maximum amplitude computed by the shallow water model reaches $80 \mathrm{~cm}$ in Ponta Delgada (Azores). Significant amplitudes are also found at Madeira (Funchal and Porto Santo).

mance and to allow for its use in more computing intensive problems.

NSWING uses the discretization and explicit leap-frog finite difference scheme to solve the shallow water equations in spherical and Cartesian coordinates developed by Liu et al. (1998). The calculations presented here use spherical coordinates and a time step of $2.5 \mathrm{~s}$. The model ran 7200 time steps, corresponding to a Courant number $\sim 0.45$ for 18 points of interest located along the coasts of Iberia, Africa, and the Atlantic islands, with a total propagation time of $5 \mathrm{~h}$ (see Fig. 6 and Table 5 for locations).

The synthesis of the tsunami waveform $\eta_{m}\left(t_{t}\right)$ at the $m$ point of interest for the time span $t_{t}$ is given by a superposition principle:

$\eta_{m}\left(t_{t}\right)=\sum_{i=1}^{\mathrm{nl}} \sum_{j=1}^{\mathrm{nc}} G_{i j}^{\mathrm{m}}\left(t_{t}\right) h_{i j}$

where $G_{i j}^{\mathrm{m}}\left(t_{t}\right)$ is the empirical Green's function computed by the shallow water model for $t$ time steps, $(\mathrm{nl} \times \mathrm{nc})$ is the set of unit sources, and $h_{i j}$ is the amplitude of the initial water displacement attributed to the $i j$ unit source. The computation of the synthetic tsunami waveforms at each POI comprises the selection of the source parameters from the seismic catalogue, the computation of the corresponding elastic deformation of the seafloor $h_{i j}$, and the use of Eq. (7) to synthetize the corresponding wave heights at $30 \mathrm{~m}$ water depth.

\section{Tsunami hazard assessment}

Tsunami hazard is computed in terms of wave height at each POI. Because we ran a linear approach and the depths of the different points of interest are variable, we use Green's law
(Green, 1838) which expresses the conservation of wave energy flux, to reduce all amplitudes to comparable depths:

$\frac{\eta_{\mathrm{s}}}{\eta_{\mathrm{d}}}=\left(\frac{H_{\mathrm{d}}}{H_{\mathrm{s}}}\right)^{\frac{1}{4}}$

where $\eta_{\mathrm{s}}$ and $\eta_{d}$ represent the wave amplitudes in shallow and deep water, respectively, while $H_{\mathrm{S}}$ and $H_{\mathrm{d}}$ are the corresponding water depths. We assume that the nonlinear effects can be neglected up to $30 \mathrm{~m}$ depth, and so we fix $H_{\mathrm{s}}$ to $30 \mathrm{~m}$. The amplitude $\eta_{\mathrm{s}}$ is then computed using Eq. (8) and the water depth at the POI $\left(H_{\mathrm{d}}\right)$. This procedure ensures the comparability between wave amplitude estimations for different POIs.

In Fig. 6, the maximum amplitude at each POI is plotted against the event number in the catalogue. Results show that the largest amplitudes occur in the Azores (Ponta Delgada, see Fig. 1) and Madeira Island. These results are compatible with the maximum observed amplitudes of the tsunami on 25 November 1941 (Baptista et al., 2016), see Table 6. Along the western Iberian coast, the wave heights decrease fast north of Douro (Portugal), with values that do not exceed $20 \mathrm{~cm}$ in Vigo (Spain). However, south of Douro and along the southern Portuguese coast (Vila do Bispo to Vila Real de Santo António), the wave heights can reach up to $60 \mathrm{~cm}$. In the Atlantic coast of Morocco wave heights between Essaouira and Casablanca can reach $0.5 \mathrm{~m}$, decreasing to less than $0.2 \mathrm{~m}$ towards Safi (see Fig. 1 for locations).

In Fig. 7 we present the estimated relative frequency of tsunami wave heights for four points of interest used in this study. These points are Ponta Delgada in the Azores islands, the western POI of the grid, Porto Santo in Madeira archipelago, Casablanca in Morocco, and Leixões in northern Portugal (these POIs are named PDE, PRS, CSB, and 

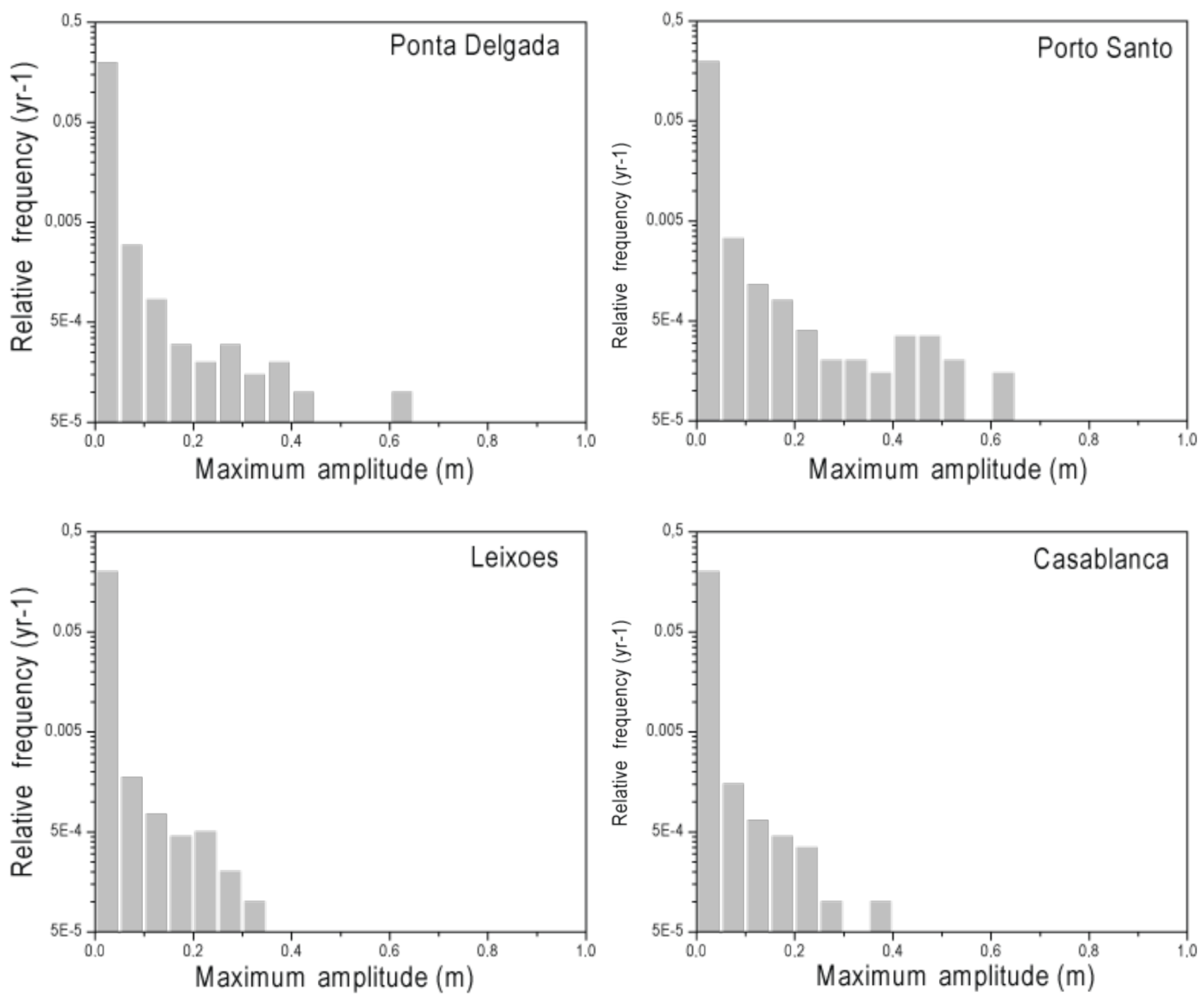

Figure 7. Estimated relative frequency of tsunami wave heights for four points of interest used in this study where the impact from Gloria sources is meaningful (see Fig. 1 for locations).

Table 5. Points of interest used in this study.

\begin{tabular}{lrrr}
\hline POI & $\begin{array}{r}\text { Longitude } \\
\left({ }^{\circ}\right)\end{array}$ & $\begin{array}{r}\text { Latitude } \\
\left({ }^{\circ}\right)\end{array}$ & $\begin{array}{r}\text { Depth } \\
(\mathrm{m})\end{array}$ \\
\hline Vigo & -08.92 & 42.23 & 009.3 \\
Huelva & -06.95 & 37.09 & 017.5 \\
Cádiz & -06.35 & 36.53 & 019.0 \\
Ceuta & -05.30 & 35.88 & 018.7 \\
Ponta Delgada & -25.66 & 37.71 & 283.8 \\
Porto Santo & -16.32 & 33.05 & 342.5 \\
Funchal & -16.92 & 32.63 & 083.0 \\
Douro & -08.72 & 41.14 & 021.8 \\
Leixões & -08.75 & 41.18 & 028.9 \\
Nazaré & -09.11 & 39.60 & 057.2 \\
Cascais & -09.34 & 38.62 & 012.5 \\
Vila do Bispo & -08.97 & 37.09 & 023.2 \\
Armação de Pêra & -08.37 & 37.05 & 017.3 \\
Faro & -07.91 & 36.96 & 005.4 \\
Vila Real & -07.41 & 37.13 & 014.4 \\
Casablanca & -07.77 & 33.58 & 021.7 \\
Essaouira & -09.81 & 31.51 & 025.0 \\
Gibraltar & -05.36 & 36.10 & 261.9 \\
\hline
\end{tabular}

LXS respectively in Fig. 1). These four points are located west, south, southeast, and northeast of the source, thus giving an azimuthal overview of the study domain. The results presented in Fig. 7 show that the highest amplitudes of $0.8 \mathrm{~m}$ occur at Azores and Madeira islands. However, these values correspond to low frequency events $\left(\sim 10^{3}\right.$ years $)$. Towards the east the amplitudes are smaller, not exceeding $0.5 \mathrm{~m}$.

\section{Discussion and conclusions}

The results presented in Fig. 6 show that the tsunamis from Gloria Fault pose a minor threat to the northern part of the northeast Atlantic basin (north of Douro) and towards the Strait of Gibraltar. Also, the amplitudes in southern Spain (Huelva and Cádiz) do not exceed $40 \mathrm{~cm}$. The potential impacts are limited to the interaction with harbours. In the Azores (Ponta Delgada) and Madeira (Funchal and Porto Santo), wave heights can reach $80 \mathrm{~cm}$, leading to the need of evacuation of low coastal areas in case of an event. Along the Moroccan coast the wave amplitudes are maximum in Casablanca, decreasing towards south. Sea level rising in the next decades, because of global warming, will add to 
Table 6. Recorded tsunami amplitudes for the 1939, 1941, and 1975 events and maximum predicted tsunami amplitudes in $20 \mathrm{kyr}$ cata$\log$.

\begin{tabular}{lrrrr}
\hline POI & 1939 & 1941 & 1975 & $\begin{array}{r}\text { Max } \\
(20 \mathrm{kyr})\end{array}$ \\
\hline Vigo & & - & 0.02 & 0.35 \\
Huelva & & - & - & 0.27 \\
Cádiz & & - & 0.03 & 0.21 \\
Ceuta & - & 0.04 & 0.03 \\
P Delgada & 0.08 & 0.20 & - & 1.39 \\
P Santo & & - & - & 0.95 \\
Funchal & 0.08 & - & 0.67 \\
Douro & & - & - & 0.39 \\
Leixões & 0.20 & - & 0.40 \\
Nazaré & & - & - & 0.47 \\
Cascais & 0.11 & 0.24 & 0.45 \\
V Bispo & - & - & 0.55 \\
Armação & - & - & 0.52 \\
Faro & - & - & 0.47 \\
VRSA & & - & - & 0.24 \\
Casablanca & 0.09 & - & 0.44 \\
Essaouira & 0.12 & - & 0.34 \\
Gibraltar & - & - & 0.06 \\
\hline
\end{tabular}

these amplitudes. These results agree with what is known from the historical record. Strike slip tsunamis generated at the Azores-Gibraltar plate boundary were observed during the 20th century but with limited impact on the neighbouring coastal areas (Baptista and Miranda, 2009; Baptista et al., 2016). The largest impact was observed during the 1941 event, associated with the harbour of Leixões in the north of Portugal.

The approach described here is easy to implement in all geological environments where there is enough information to compute a synthetic earthquake catalog. The case study presented here corresponds to a favourable situation where the fault geometry is supposed to be simple, there is a well constrained long-term tectonic slip, and there are several large instrumental tsunami events, which can be used to challenge the synthetic results obtained by numerical modelling. When dealing with geological situations of increased complexity there will be the need for additional a priori constraints for the establishment of the catalog of events.

In the case of studies dealing with near field cases, the variability in slip should be taken into account in the building of the synthetic catalogue and in the computation of the ocean bottom deformation needed to initiate the tsunami simulation.

In this study, we assume perfect seismic coupling $(\chi=$ 1.0). Other choices could be made. Bird and Kagan (2004) proposed for slow oceanic transform faults $\left(u<39 \mathrm{~mm} \mathrm{yr}^{-1}\right)$ that $\chi \sim 0.93$ for a seismogenic thickness of $14 \mathrm{~km}$. Since the synthesis of the tsunami waveforms Eq. (7) is linear, a different seismic coupling parameter can be easily accommodated in the hazard curves by considering an appropriate time span for the synthetic catalogue. The size of the initial deformation of the seafloor is dependent on the value of the rigidity. For the case of the Azores-Gibraltar plate boundary, rigidity has been differently evaluated in a significant way: Johnston (1996) uses $\mu=6.5 \times 10^{10} \mathrm{~Pa}$. Since $\mu=\rho V_{S}^{2}$, Stich et al. (2007) propose a slightly higher value $\mu=7.0 \times 10^{10} \mathrm{~Pa}$. Heinrich et al. (1994) assume a lower value, $\mu=4 \times 10^{10} \mathrm{~Pa}$. The choice of this parameter will influence the result in terms of tsunami hazard.

The numerical modelling of tsunami waveforms based on the use of the empirical Green's function is a simple and efficient approach. The direct determination of a catalog of tsunami waveforms provides a direct description of the hazard, which is described as an empirical histogram of the frequency of occurrence of a given tsunami amplitude. Information concerning expected frequencies or the incorporation of the effect of tides can easily be added to this methodology, providing planners and emergency managers with the information they need to develop tsunami resilience of the coastal populations.

Finally, it is worth pointing out that the instrumental observations in the 20th century correspond to the realization of low frequency seismic and tsunami events but not to the maximum predicted wave heights as shown in Table 6.

Code and data availability. The corresponding benchmarks can be obtained from the authors, and the NSWING code is available at https://github.com/joa-quim/NSWING (Miranda and Luis, 2017).

Competing interests. The authors declare that they have no conflict of interest.

Acknowledgements. The authors wish to thank Andrzej Kijko for providing the MATLAB code and the reviewers for their suggestions for improving this paper as well as the reviewers that contributed to improve this work. This study received funding from project ASTARTE - Assessment Strategy and Risk Reduction for Tsunamis in Europe, grant 603839 - FP7, and from the EU project TSUMAPS NEAM, agreement number ECHO/SUB/2015/718568/PREV26.

Edited by: Mauricio Gonzalez

Reviewed by: José A. Alvarez-Gómez and one anonymous referee

\section{References}

Baptista, M. A., Miranda, J. M., Batllo, J., and Macia, R.: North East Atlantic tsunamis related with Gloria fault, in: AGU Fall Meeting Abstracts, 5-9 December 2011, San Francisco, California, USA, Vol. 1, p. 1530, 2011. 
Baptista, M. A. and Miranda, J. M.: Revision of the Portuguese catalog of tsunamis, Nat. Hazards Earth Syst. Sci., 9, 25-42, https://doi.org/10.5194/nhess-9-25-2009, 2009.

Baptista, M. A., Miranda, P. M. A., Miranda, J. M., and Victor, L. M.: Constrains on the source of the 1755 Lisbon tsunami inferred from numerical modelling of historical data on the source of the 1755 Lisbon tsunami, J. Geodyn., 25, 159-174, https://doi.org/10.1016/S0264-3707(97)00020-3, 1998.

Baptista, M. A., Miranda, J. M., Batlló, J., Lisboa, F., Luis, J., and Maciá, R.: New study on the 1941 Gloria Fault earthquake and tsunami, Nat. Hazards Earth Syst. Sci., 16, 1967-1977, https://doi.org/10.5194/nhess-16-1967-2016, 2016.

Bird, P. and Kagan, Y. Y.: Plate-Tectonic Analysis of Shallow Seismicity: Apparent Boundary Width, Beta, Corner Magnitude, Coupled Lithosphere Thickness, and Coupling in Seven Tectonic Settings, B. Seismol. Soc. Am., 94, 2380-2399, https://doi.org/10.1785/0120030107, 2004.

Blaser, L., Krüger, F., Ohrnberger, M., and Scherbaum, F.: Scaling relations of earthquake source parameter estimates with special focus on subduction environment, B. Seismol. Soc. Am., 100, 2914-2926, 2010

Buforn, E., Udias, A., and Colombas, M.: Seismicity source of the mechanisms and tectonics of the Azores-Gibraltar plate boundary, Tectonophysics, 152, 89-118, https://doi.org/10.1016/00401951(88)90031-5, 1988.

Carvalho, A., Reis, C., and Vales, D. Source and high-frequency decay parameters for the Azores region for stochastic finite-fault ground motion simulations, B. Earthq. Eng., 14, 1885-1902, 2016.

Cornell, C. A.: Engineering seismic risk analysis, B. Seismol. Soc. Am., 58, 1583-1606, 1968.

Fernandes, R. M. S., Ambrosius, B. A. C., Noomen, R., Bastos, L., Wortel, M. J. R., Spakman, W., and Govers, R.: The relative motion between Africa and Eurasia as derived from ITRF2000 and GPS data, Geophys. Res. Lett., 30, 1828, https://doi.org/10.1029/2003GL017089, 2003.

Geist, E. L. and Lynett, P. J.: Source processes for the probabilistic assessment of tsunami hazards, Oceanography, 27, 86-93, https://doi.org/10.1007/s11069-005-4646-z, 2014.

Geist, E. L. and Parsons, T.: Probabilistic analysis of tsunami hazards, Nat. Hazards, 37, 277-314, https://doi.org/10.1007/s11069005-4646-z, 2006.

Geli, L. and Sclater, J.: On the depth of oceanic earthquakes: Brief comments on "The thermal structure of oceanic and continental lithosphere", by McKenzie, D., Jackson, J. and Priestley, K., Earth Planet. Sc. Lett., 233, [2005], 337-349, Earth Planet. Sc. Lett., 265, 766-772, https://doi.org/10.1016/j.eps1.2007.08.029, 2008.

González, F. I., Geist, E. L., Jaffe, B., Kânoğlu, U., Mofjeld, H., Synolakis, C. E., Titov, V. V., Arcas, D., Bellomo, D., Carlton, D., Horning, T., Johnson, J., Newman J., Parsons, T., Peters, R., Peterson, C., Priest, G., Venturato, A., Weber, J., Wong, F., and Yalciner, A.: Probabilistic tsunami hazard assessment at seaside, Oregon, for near-and far-field seismic sources, J. Geophys. Res.Oceans, 114, C11023, https://doi.org/10.1029/2008JC005132, 2009.

Green, G.: On the motion of waves in a variable canal of small depth and width, Transactions of the Cambridge Philosophical Society, 6, p. $457,1838$.
Gutenberg, B. and Richter, C. F.: Seismicity of the earth and associated phenomena, Princeton University Press, Princeton, USA, 273 pp., 1949.

Hanks, T. C. and Kanamori, H.: A moment magnitude scale, J. Geophys. Res., 84, 2348-2350, https://doi.org/10.1029/JB084iB05p02348, 1979.

Heinrich, P., Baptista, M. A., and Miranda, P.: Numerical simulation of the 1969 tsunami along the Portuguese coasts. Preliminary results, Sci. Tsunami Hazards, 12, 3-23, 1994.

Johnston, A. C.: Seismic moment assessment of earthquakes in stable continental regions. III. New Madrid 1811-1812, Charleston 1886, and Lisbon 1755, Geophys. J. Int., 126, 314344, https://doi.org/10.1111/j.1365-246X.1996.tb07028.x, 1996.

Kaabouben, F., Brahim, A. I. ,Toto, E., Baptista, M. A., Miranda, J. M., Soares, P., and Luis, J. F.: On the focal mechanism of the 26.05.1975 North Atlantic event contribution from tsunami modeling, J. Seism., 12, 575-583, https://doi.org/10.1007/s10950008-9110-6, 2008.

Kanamori, H. and Anderson, D.: Theoretical basis of some empirical relations in seismology, B. Seismol. Soc. Am., 65, 10731095, 1975.

Kijko, A. and Graham, G.: Parametric-historic procedure for probabilistic seismic hazard analysis Part I: estimation of maximum regional magnitude mmax, Pure Appl. Geophys., 152, 413-442, https://doi.org/10.1007/s000240050218, 1998.

Laughton, A. S., Whitmarsh, R. B., Rusby, J. S. M., Somers, M. L., Revie, J., McCartney, B. S., and Nafe, J. E.: A Continuous EastWest Fault on the Azores-Gibraltar Ridge, Nature, 237, 217-220, https://doi.org/10.1038/237217a0, 1972.

LeVeque, R. J., Waagan, K., González, F. I., Rim, D., and Lin, G.: Generating random earthquake events for probabilistic tsunami hazard assessment, Pure Appl. Geophys., 173, 3671-3692, https://doi.org/10.1007/s00024-016-1357-1, 2016.

Liu, P. L.-F., Woo, S.-B., and Cho, Y.-S.: Computer programs for tsunami propagation and inundation, Technical report, Cornell University, available at: http://tsunamiportal.nacse.org/ documentation/COMCOT_tech.pdf (last access: January 2017), 1998.

Luis, J. F., and Miranda, J. M.: Reevaluation of magnetic chrons in the North Atlantic between $35^{\circ} \mathrm{N}$ and $47^{\circ} \mathrm{N}$ : implications for the formation of the Azores Triple Junction and associated plateau, J. Geophys. Res., 113, B10105, https://doi.org/10.1029/2007JB005573, 2008.

Lynnes, C. S., and Ruff, L. J.: Source process and tectonic implications of the great 1975 North Atlantic earthquake, Geophys. J. Int., 82, 497-510, https://doi.org/10.1111/j.1365246X.1985.tb05148.x, 1985.

Manighetti, I., Campillo, M., Bouleya, S., and Cottona, F.: Earthquake scaling, fault segmentation, and structural maturity, Earth Planet. Sc. Lett., 253, 429-438, https://doi.org/10.1016/j.eps1.2006.11.004, 2007.

Matias, L. M., Cunha, T., Annunziato, A., Baptista, M. A., and Carrilho, F.: Tsunamigenic earthquakes in the Gulf of Cadiz: fault model and recurrence, Nat. Hazards Earth Syst. Sci., 13, 1-13, https://doi.org/10.5194/nhess-13-1-2013, 2013.

McKenzie, D., Jackson, J., and Priestley, K.: Thermal structure of oceanic and continental lithosphere, Earth Planet. Sc. Lett., 233, 337-349, https://doi.org/10.1016/j.epsl.2005.02.005, 2005. 
McKenzie, D. P.: Active tectonics of the Mediterranean region, Geophys. J. Roy. Astr. S., 30, 109-185, https://doi.org/10.1111/j.1365-246X.1972.tb02351.x, 1972.

Miranda, J. M. and Luis, J.: NSWING (Non-linear Shallow Water model With Nested Grids), Instituto Dom Luiz, available at: https://github.com/joa-quim/NSWING, last access: 9 July 2017.

Miranda, J. M., Baptista, M. A., and Omira, R.: On the use of Green's summation for tsunami waveform estimation: a case study, Geophys. J. Int., 199, 459-464, https://doi.org/10.1093/gji/ggu266, 2014.

Molinari, I., Tonini, R., Lorito, S., Piatanesi, A., Romano, F., Melini, D., Hoechner, A., Gonzàlez Vida, J. M., Maciás, J., Castro, M. J., and de la Asunción, M.: Fast evaluation of tsunami scenarios: uncertainty assessment for a Mediterranean Sea database, Nat. Hazards Earth Syst. Sci., 16, 2593-2602, https://doi.org/10.5194/nhess-16-2593-2016, 2016.

Okada, Y.: Surface deformation due to shear and tensile faults in a half space, B. Seismol. Soc. Am., 75, 1135-1154, 1985.

Omira, R., Baptista, M. A., and Matias, L.: Probabilistic tsunami hazard in the Northeast Atlantic from near-and farfield tectonic sources, Pure Appl. Geophys., 172, 901-920, https://doi.org/10.1007/s00024-014-0949-x, 2015.

Power, W., Downes, G., and Stirling, M.: Estimation of tsunami hazard in New Zealand due to south American earthquakes, Pure Appl. Geophys., 164, 547-564, https://doi.org/10.1007/s00024006-0166-3, 2007.

Reis, C., Omira, R., Matias, L., and Baptista, M. A.: On the source of the 8 May 1939 Azores earthquake-tsunami observations and numerical modelling, Geomat. Nat. Haz. Risk, 1-20, https://doi.org/10.1080/19475705.2016.1218944, 2016.
Robinson, D. P.: A rare great earthquake on an oceanic fossil fracture zone, Geophys. J. Int., 186, 1121-1134, https://doi.org/10.1111/j.1365-246X.2011.05092.x, 2011.

Scholz, C. H.: Scaling laws for large earthquakes: consequences for physical models, B. Seismol. Soc. Am., 72, 1-14, 1982.

Sørensen, M. B., Spada, M., Babeyko, A., Wiemer, S., and Grünthal, G.: Probabilistic tsunami hazard in the Mediterranean Sea, J. Geophys. Res.-Sol. Ea., 117, 1978-2012, https://doi.org/10.1029/2010JB008169, 2012.

Stich, D., Mancilla, F. L.,Pondrelli, S., and Morales, J.: Source analysis of the February 12th 2007, Mw 6.0 Horseshoe earthquake: Implications for the 1755 Lisbon earthquake, Geophys. Res. Lett., 34, L12308, https://doi.org/10.1029/2007GL030012, 2007.

Stirling, M., Rhoades, D., and Berryman, K.: Comparison of Earthquake Scaling Relations Derived from Data of the Instrumental and Preinstrumental Era, B. Seismol. Soc. Am., 92, 812-830, 2002.

Udias, A., Lopez Arroyo, A., and Mezcua, J.: Seismotectonic of the Azores Alboran region, Tectonophysics, 31, 259-289, 1976.

Wells, D. L. and Coppersmith, K. J.: New empirical relationships among magnitude, rupture length, rupture width, rupture area, and surface displacement, B. Seismol. Soc. Am., 84, 974-1002, 1994.

Wessel, P., Smith, W. H., Scharroo, R., Luis, J., and Wobbe, F.: Generic mapping tools: improved version released, Eos Trans. Am. Geophys. Un., 94, 409-410, 2013. 